\title{
Načrtovanje in strukturiranje prehodov med različnimi ravnmi izobraževanja za osebe s posebnimi potrebami
}

\author{
Mateja Maljevac \\ Center IRIS \\ mateja.maljevac@center-iris.si
}

\begin{abstract}
Vključevanje oseb s posebnimi potrebami v sistem vzgoje in izobraževanja predstavlja velik izziv tako za njih same kot za njihove družinske člane, strokovne delavce in vse, ki se bodo $v$ procesu vzgoje in izobraževanja na kakršen koli način srečevali z njimi. Skrbno načrtovanje in dobro strukturiranje prehodov med različnimi ravnmi ali programi izobraževanja omili stiske in zagate vseh vpletenih. $V$ prispevku predstavljamo priporočila za načrtovanje in strukturiranje prehodov, s poudarkom na potrebah uporabnika. Osvetljujemo tudi naloge in vloge posameznih strokovnih delavcev ter smernice podkrepimo s študijo primera dobre prakse. Primer dobre prakse zajema celoten prikaz načrtovanja in strukturiranja prehoda otroka s slabovidnostjo iz programa za predšolske otroke s prilagojenim izvajanjem in z dodatno strokovno pomočjo v izobraževalni program devetletne osnovne šole s prilagojenim izvajanjem in z dodatno strokovno pomočjo.
\end{abstract}

Ključne besede: osebe s posebnimi potrebami, prehodi, načrtovanje in strukturiranje, primer dobre prakse

\section{Uvod}

Prehod iz doma v vrtec, prehodi med različnimi ravnmi in programi izobraževanja ter končno prehod iz sistema vzgoje in izobraževanja na trg dela predstavljajo za posameznika ključne mejnike v življenju. Pri prehodih oz. tranzicijah razmišljamo predvsem o tem, da oseba vstopa iz varnega, znanega okolja v zanj nove, še neznane situacije. Če pri osebah z normativnim razvojem prehodi potekajo samoumevno, tekoče in običajno brez večjih težav pri vključevanju v novo situacijo, temu ni tako, ko govorimo o osebah s posebnimi potrebami. Pri teh je potrebno prehode skrbno načrtovati in jih strukturirati, da ne izzovejo neželenih vedenj v obliki čustvenih in vedenjskih težav.

\section{Teoretični del}

\section{Vrste prehodov $v$ slovenskem šolskem sistemu}

Ko govorimo o prehodih med različnimi ravnmi izobraževanja v Republiki Sloveniji, se opiramo predvsem na klasifikacijo znotraj zakonodajnega okvira 
Zakona o usmerjanju otrok s posebnimi potrebami (2011), ki v 5. členu navaja, da lahko izobraževanje otrok s posebnimi potrebami poteka po:

- programu za predšolske otroke s prilagojenim izvajanjem in z dodatno strokovno pomočjo,

- prilagojenem programu za predšolske otroke,

- vzgojno-izobraževalnih programih s prilagojenim izvajanjem in z dodatno strokovno pomočjo,

- prilagojenih programih vzgoje in izobraževanja z enakovrednim izobrazbenim standardom,

- prilagojenih programih vzgoje in izobraževanja z nižjim izobrazbenim standardom,

- posebnem programu vzgoje in izobraževanja za otroke z zmerno, težjo in težko motnjo $v$ duševnem razvoju in drugih posebnih programih $(v$ nadaljevanju posebni program vzgoje in izobraževanja),

- vzgojnih programih.

\section{Načrtovanje in strukturiranje prehodov}

Skrbno načrtovanje in strukturiranje prehodov med različnimi programi vzgoje in izobraževanja zmanjšuje stres, ki ga doživljajo vsi vpleteni pri delu z osebo s posebnimi potrebami: strokovni delavci, družina in posameznik sam. Zupančičeva in Kavčičeva (2007) sta na podlagi raziskave ugotovili, da so zgodnji učni dosežki otrok med drugim odvisni tudi od tega, kako se otroci prilagajajo na novo socialno okolje v novi šolski situaciji. Prilagajanje na šolo je pomembno, ker otrokove izkušnje v prvem razredu predstavljajo temelj nadaljnjega šolanja. Hkrati pa je pomembna sama prilagoditev in priprava fizičnega ter socialnega okolja, ko govorimo o otrocih s posebnimi potrebami, da bi zmanjšali pojavnost negativnih občutij in odklonskih prvih izkušenj z izbrano institucijo.

Mohorko (2016 v Čelešnik Kozamernik in Češarek 2020) proces prehoda med posameznimi programi in ravnmi izobraževanja razdeli na več korakov, ki zajemajo: celostno oceno otroka, podporo družini, prvi sestanek na izbrani ustanovi, prilagajanje šolskega okolja, predstavitev uporabnika, prilagoditev metod dela kolektivu pred začetkom šolskega leta, spoznavanje okolja pred pričetkom šole, izdelavo individualiziranega programa in pripravo vrstnikov. O potrebi po senzibilizaciji socialnega okolja na več ravneh in o tem, da uspešna inkluzija ni samoumevna, govorita tudi Maljevčeva in Žuničeva (2017), ki med drugim opozorita na pomen podpore strokovnim delavcev ves čas, ko je otrok s posebnimi potrebami vključen v sistem vzgoje in izobraževanja. 
Študije različnih raziskovalcev (npr. Zupančič, Podlesek in Kavčič 2018; Maljevac 2018) kažejo, da so osebnostne značilnosti posameznika tiste, ki imajo največjo napovedno vrednosti pri socialnem prilagajanju in prilagoditvenem vedenju posameznika $v$ različnih situacijah, tako $v$ primeru otrok $z$ normativnem razvojem kot otrok s posebnimi potrebami. Maljevčeva (2018) predlaga, da se pri strokovnem delu z otroki s posebnimi potrebami dopušča večja fleksibilnost $v$ smislu strokovnih obravnav različnih profilov strokovnih delavcev, ki imajo dodatna znanja s področja posebnih potreb, na vseh ravneh, torej tudi pri tranzicijskih postopkih. O fleksibilnosti razpravlja zaradi večje potrebe po personalizaciji, upoštevanju konkretnih potreb posameznika in zmanjševanju rigidnosti ter uniformiranosti. Posebej izpostavi pomen svetovalne storitve kot oblike dodatne strokovne pomoči, v okviru katere se najlažje izpeljejo tudi aktivnosti tranzicijskih programov.

Zakon o varstvu osebnih podatkov (2007) v več členih omejuje prost pretok informacij in podatkov o posamezniku med strokovnimi delavci in med institucijami. Zato je pred izvedbo korakov tranzicije nujno potrebno pridobiti soglasje staršev oz. uradnih skrbnikov mladoletne osebe za to, da se informacije o posamezniku v procesu tranzicije lahko posredujejo izbrani ustanovi. Mohorko (2016 v Čelešnik Kozamernik in Češarek 2020) predlaga, da se ustanovo na prihod otroka s slepoto in slabovidnostjo pripravi na način, da se pripravi t. i. tranzicijska mapa, ki vsebuje podatke o celostni oceni posameznika, potrebnih prilagoditvah in pripomočkih.

V primeru, da ima oseba več senzornih motenj, ovir oz. primanjkljajev, kot sta npr. gluhota in slepota, Belote (2004) podaja naslednja priporočila pri načrtovanju prehodov:

- izbira fiksnega datuma prehoda,

- priprava zbirnika materialov, ki jih učenec uporablja (vključno s komunikacijskim sistemom),

- seznanitev učenca z novo institucijo,

- srečanje dveh strokovnih timov (obstoječega in bodočega),

- če je možno, naj se ne zamenjajo vsi strokovni delavci hkrati (npr. logoped, učitelj orientacije in mobilnosti ...),

- postavitev jasnih in visokih ciljev že od samega začetka vključitve v nov program ali v novo ustanovo.

\section{Učenci s slepoto in slabovidnostjo oz. z okvaro vidne funkcije}

$\checkmark$ empiričnem delu naloge bomo predstavili študijo primera prehoda otroka s slabovidnostjo iz programa za predšolske otroke s prilagojenim izvaja- 
njem in z dodatno strokovno pomočjo $v$ izobraževalni program devetletne osnovne šole $s$ prilagojenim izvajanjem in $z$ dodatno strokovno pomočjo, zato uvodoma podajamo opredelitev slabovidnosti.

$V$ svetu ne obstaja enotna definicija slepote, slabovidnosti in okvare vidne funkcije, $v$ grobem pa lahko opredelitve razdelimo na medicinske definicije (npr. definicija Svetovne zdravstvene organizacije, slovenska definicija razširjenega strokovnega kolegija za okulistiko (But 2005)) in pedagoške definicije (npr. Kriteriji za opredelitev vrste in stopnje primanjkljajev, ovir oz. motenj otrok s posebnimi potrebami, ki jih je pripravil Zavod Republike Slovenije za šolstvo). V poglavju »Slepi in slabovidni otroci oz. otroci z okvaro vidne funkcije« najdemo pedagoško definicijo slepote in slabovidnosti oz. okvare vidne funkcije (Stirn Kranjc idr. 2015). Slovenska pedagoška definicija slepote in slabovidnosti oz. okvare vidne funkcije $v$ našem šolskem prostoru služi kot pravna podlaga pedagoškemu delu $z$ učenci s posebnimi potrebami in z njihovim okoljem, hkrati pa se od medicinskih definicij razlikuje po tem, da opredeljuje tudi okvaro vidne funkcije, česar pa pri medicinskih opredelitvah še ne zasledimo. V nadaljevanju predstavljamo definicijo slabovidnosti, ki jo bomo uporabili za potrebe naše raziskave (Stirn Kranjc idr. 2015, 8-9):

Slepi in slabovidni otroci ter otroci z okvaro vidne funkcije so otroci, ki imajo zmanjšano ostrino vida, zoženo vidno polje ali okvaro vidne funkcije. Merilo za oceno vidnega polja je izvid perimetrije.

Slabovidni otrok ima ostrino vida od 5 do 30 odstotkov ali zoženo vidno polje $v$ vseh meridijanih nad 10 do vključno 20 stopinj okrog fiksacijske točke, ne glede na ostrino vida. Razlikujemo zmerno slabovidnega in težko slabovidnega otroka.

Zmerno slabovidni otrok ima ostrino vida od 10 do 30 odstotkov. Potrebuje delno prilagojeno vzgojno-izobraževalno okolje in po potrebi prilagojene učne in vzgojne pripomočke, specialni trening na področju komunikacijskih tehnik in/ali orientacije. Ob ustreznih pogojih sprejema vidne informacije in dela po metodi za slabovidne. Lahko ohrani hitrost dela kot videči vrstniki, vendar s prilagoditvijo gradiv ali uporabo pripomočkov za branje.

Težko slabovidni otrok ima ostrino vida od pet do manj kot deset odstotkov ali zoženo vidno polje nad deset do vključno 20 stopinj okrog fiksacijske točke, ne glede na ostrino vida. Potrebuje prilagojeno vzgojnoizobraževalno okolje in didaktične pripomočke. Potrebuje specialni trening na področju komunikacijskih tehnik, orientacije in socialnih veščin. Pretežni del učenja poteka z vidno informacijo, dela po metodi za 
slabovidne. Bere lahko črni tisk s prilagoditvijo gradiva ali uporabo pripomočkov, vendar je njegovo branje ovirano in počasnejše.

\section{Vloga strokovnega centra za celostno podporo otrokom in mladostnikom z okvaro vida pri prehodih}

Osebe z okvaro vida potrebujejo celostno podporo v različnih življenjskih obdobjih. Sistematična podpora družini, otrokom in vzgojno-izobraževalnim institucijam je nujna od rojstva dalje, saj tako celostno vplivamo na razvoj otroka. Dve izmed področij delovanja strokovnega centra za celostno podporo otrokom in mladostnikom z okvaro vida $v$ Sloveniji sta tudi podpora in pomoč vrtcem ter šolam in svetovanje ter izobraževanje za starše in strokovnjake. V obeh sklopih se lahko načrtujejo tranzicije med različnimi ravnmi in programi izobraževanja, ki vključujejo seznanitev vrtca, šole pred vključitvijo otroka ali mladostnika po izvedbi celostne ocene otroka kadar koli med šolskim letom (Center IRIS 2020). Zlasti v tujini (npr. Texas School for Blind and Visually Impaired b. I.) se v strokovnih centrih poudarja aktivnemu sodelovanju samega otroka ali mladostnika pri načrtovanju prehoda v smislu razvijanja veščin opolnomočenja v okviru razširjenega kurikula za slepe in slabovidne, kar predstavlja nadgradnjo našega sistema načrtovanja in strukturiranja prehodov. Kontinuirana obravnava otroka skozi različna obdobja sledi osnovnemu cilju, to je dobro rehabilitiran posameznik, ki se lahko aktivno vključuje v družbo na več ravneh, tudi na sam trg dela. Cavenaughova in Giesen (2012) govorita o tem, da načrtovanje prehodov ne vpliva le na doseženo akademsko izobrazbo, pač pa tudi na razvoj in dvig drugih specifičnih kompetenc ter veščin, kot so npr. poklicna orientacija, iskanje službe, razvoj socialnih veščin, karierni razvoj, delovne izkušnje ipd.

\section{Opredelitev raziskovalnega problema, namen in cilji raziskave}

Otroci s posebnimi potrebami, natančneje otroci s slepoto, slabovidnostjo ali z okvaro vidne funkcije, potrebujejo zaradi izgube primarnega čutila, preko katerega zaznavajo svet, posebej načrtovan in strukturiran prehod med različnimi ravnmi in programi izobraževanja.

Njihova zmožnost socialnega prilagajanja in učna uspešnost v prvem razredu sta močno povezani (Zupančič in Kavčič 2007), iz česar lahko predpostavljamo, da bodo otroci, pri katerih bo prehod iz programa za predšolske otroke s prilagojenim izvajanjem in $z$ dodatno strokovno pomočjo $v$ program devetletne osnovne šole $s$ prilagojenim izvajanjem in $z$ dodatno strokovno pomočjo potekal načrtno in strukturirano, učno uspešnejši v primerjavi z vrstniki, ki bodo med programi prehajalo spontano in nenačrtovano. Glavni na- 
men naše raziskave je pomagati pri dvigu kakovosti dela na področju načrtovanja prehodov otrok s slepoto, slabovidnostjo in okvaro vidne funkcije, ki se skozi prakso kaže kot eno izmed kritičnih področij.

Cilji raziskave so:

- definirati ključne korake pri različnih prehodih v slovenskem šolskem sistemu za osebe s posebnimi potrebami;

- ugotoviti, kdo vse sodeluje pri načrtovanju in izvedbi procesa prehoda;

- ugotoviti, katere so najpomembnejše informacije, ki naj bodo zapisane $v$ tranzitni mapi učenca;

- opisati primer dobre prakse prehoda otroka s slabovidnostjo iz programa za predšolske otroke $s$ prilagojenim izvajanjem in $z$ dodatno strokovno pomočjo $v$ izobraževalni program devetletne osnovne šole s prilagojenim izvajanjem in z dodatno strokovno pomočjo.

\section{Raziskovalna vprašanja}

V raziskavi smo si zastavili tri glavna raziskovalna vprašanja:

1. Kateri so ključni koraki pri načrtovanju prehoda med različnimi ravnmi in programi vzgoje in izobraževanja?

2. Katere strokovne delavce je potrebno izobraziti oz. jim podati osnovne informacije o otrokovih posebnih potrebah in kdo naj to izvede?

3. Kakšen način podajanja ključnih informacij o otroku je za učitelje najoptimalnejši?

\section{Metoda}

Uporabljena je deskriptivna metoda empiričnega pedagoškega raziskovanja. Zasnovana je kot kvalitativna študija primera z uporabo več virov podatkov.

\section{Udeleženci raziskave}

$\checkmark$ raziskavo smo vključili otroka s slabovidnostjo, njegove starše, strokovne delavce vrtca, $v$ katerega je bil otrok vključen, in strokovne delavce osnovne šole, ki jo bo otrok obiskoval v prihodnjem šolskem letu.

\section{Postopek zbiranja in obdelave podatkov}

Za začetek smo vzpostavili kontakt s starši in jih hkrati prosili za soglasje za sodelovanje $v$ raziskavi. Pojasnili smo jim namen in postopek raziskave ter poudarili, da bo identiteta otroka skrita. Starši so se s sodelovanjem otroka v 
raziskavi strinjali, zato smo zanj zaprosili še vrtec in šolo, $\mathrm{s}$ katerima smo načrtovali program prehoda. Analizirali smo naslednjo dokumentacijo otroka: strokovno mnenje, odločbo o usmeritvi, individualizirani program dela, zaključna poročila o izvajanju individualiziranih programov, poročilo vrtca o otroku, oceno funkcionalnosti vida in oftalmološke izvide.

Vsak korak prehoda smo beležili na dveh ravneh: časovni izvedbi koraka ter temeljnih vsebinskih poudarkih posameznega koraka. Po uspešno izpeljanih korakih prehoda učenca iz programa za predšolske otroke $s$ prilagojenim izvajanjem in $z$ dodatno strokovno pomočjo $v$ program devetletne osnovne šole s prilagojenim izvajanjem in z dodatno strokovno pomočjo smo podatke kvalitativno analizirali in izdelali shemo korakov prehoda ter oblikovali zbirnik osnovnih informacij o otroku, ki smo ga posredovali tudi učenčevi šoli.

\section{Rezultati in interpretacija}

V nadaljevanju besedila predstavljamo primer otroka s slabovidnostjo in aktivnosti, ki smo jih v partnerstvu s starši in z otrokovim vrtcem izpeljali za uspešen prehod iz programa za predšolske otroke s prilagojenim izvajanjem in $z$ dodatno strokovno pomočjo $v$ program devetletne osnovne šole $s$ prilagojenim izvajanjem in z dodatno strokovno pomočjo.

Zaradi zaščite in varovanja osebnih podatkov otroka in njegove družine predstavljamo le najrelevantnejše podatke o otrokovih posebnih potrebah. Podatke o družinski anamnezi, o otrokovem socialnem in vrtčevskem okolju smo izpustili, saj bi bil v nasprotnem primeru zelo lahko identificiran.

Temeljne značilnosti otrokovih posebnih potreb, ki so potrebne za razumevanje načrtovanja prehoda, predstavljamo v nadaljevanju.

\section{Značilnosti otrokovih posebnih potreb}

Iz otrokove zdravstvene in pedagoške dokumentacije lahko razberemo, da se uvršča med zmerno slabovidne otroke. Po diagnozi ima opredeljen horizontalni nistagmus, ${ }^{1}$ okularni albinizem, ${ }^{2}$ fotofobijo ${ }^{3}$ in astigmatizem. ${ }^{4}$ Vidna ostrina na daljavo je okrog $16 \%$, vidna ostrina na bližino $40 \%$. Otrok dobro loči barve, kontrastna občutljivost je znižana. Ocena funkcionalnosti vida

\footnotetext{
${ }^{1}$ Nistagmus: nehoteni ritmični gibi zrkel (»Nistagmus« b. I.).

${ }^{2}$ Albinizem: anomalija pigmentacije zaradi pomanjkanja melanina, ki se kaže kot apigmentacija ali hipopigmentacija kože, las in šarenice $z$ vrsto očesnih okvar in se prenaša dedno (»Albinizem« b. I.).

${ }^{3}$ Fotofobija: vizualna preobčutljivost na svetlobo (»Fotofobija« b. I.).

${ }^{4}$ Astigmatizem: neenaka ukrivljenost lomnih površin očesa, zlasti roženice, $v$ različnih meridianih, ki povzroča neoster vid (»Astigmatizem«b. l.).
} 
kaže tudi na okvaro globinskega vida, medtem ko je vidno polje brez posebnosti. Otrok zanesljivo reagira na vizualne dražljaje. Locira predmet, ga vzame in ustrezno premakne po navodilu. Obrača se, da bi videl predmete, ki so izven vidnega polja. Vizualna pozornost je še vedno odkrenljiva, a se je v zadnjem letu izboljšala. Koordinacija oko-roka je razvita: manipulira s predmeti različnih velikosti, vendar je manj spreten pri funkcionalnih ročnih spretnostih. Pri ogledu knjig uporablja bralno mizico in potrebuje veliko spodbud pri poslušanju prebrane vsebine. Med usmerjeno dejavnostjo je nemiren, a posluša in ve, o čem teče beseda. Pri dečku so razvite bazične vizualne veščine (vizualna pozornost, očesni kontakt, fiksacija, sledenje, premikanje pogleda z enega na drugi vizualni dražljaj, vizualna pozornost ipd.), vendar so še vedno opazne težave z vizualno zaznavnimi funkcijami. Pri gledanju nagne glavo, ki rahlo potresava. Če je utrujen, ima težave s sledenjem snovi na vseh ravneh (odmik od teme - ne posluša, ne gleda, poveča se nemirnost). Težave s koncentracijo in odkrenljivo pozornostjo se izraziteje kažejo pri delu v skupini, individualno funkcionira precej bolje. $V$ prostorih vrtca je dobro orientiran.

Cilji individualiziranega programa dela so bili osnovani na oregonski ocenjevalni lestvici (Anderson idr. 2007).

Pri vajah vida je uspešen, a še ni navajen na sistematičnost pri opazovanju slikovnega gradiva. Dosledno uporablja korekcijska in sončna očala. Občasno potrebuje več spodbud, da nalogo opravi tako, kot se zahteva. Slabše opravi naloge, ki zahtevajo uporabo globinskega vida (npr. lovljenje žoge, nivojski prehodi). Fina motorika in z njo grafomotorika sta slabše razviti, a se je fina motorika v zadnjem letu bistveno izboljšala. Pri orientaciji v neznanem okolju potrebuje zagotovljeno dodatno varnost, prostor usvoji primerno hitro. Pri navezovanju stikov je uspešen, ima veliko prijateljev. Je izredno empatičen deček. Zna poskrbeti zase, vendar je površen pri nalogah (npr.: ne moti ga, če si narobe obrne čevlje na nogah).

Igra se pretežno vzporedno, vključuje se tudi v skupinske oblike iger; od spoznavnih vrst igre prevladuje konstrukcijska igra, najvišja dosežena raven so igre s pravili.

Kot učinkovite so se $v$ vrtcu izkazale naslednje prilagoditve, pripomočki in načini dela, za katere strokovna skupina vrtca predlaga, da se, v modificirani obliki za osnovno šolo, nadaljujejo:

- kontrastno gradivo in pripomočki,

- 30-50 \% več časa za opazovanje v primerjavi z vrstniki,

- napovedana struktura dejavnosti (kako si sledijo, jasna navodila),

- vse stvari si ogleda od blizu, individualno, ima jih možnost potipati, 
- pri delu v skupini sedi v bližini strokovne delavke,

- delo v posebnem prostoru,

- interaktivne igrače,

- bralna mizica,

- zmanjšan normativ v oddelku,

- zagotovljena dodatna varnost na sprehodih in izletih,

- izobraževanje strokovnih delavk na temo slepote in slabovidnosti,

- redno sodelovanje s starši.

\section{Aktivnosti, ki so bile izpeljane za uspešen prehod}

Pri načrtovanju prehoda smo upoštevali glavne smernice, ki jih predlagata Mohorko (2016 v Čelešnik Kozamernik in Češarek 2020) in Belote (2004), vendar v prilagojeni obliki, za katero smo ocenili, da bi bila za otroka najustreznejša (preglednica 1).

Aktivnosti priprave za prehod učenca iz programa za predšolske otroke $s$ prilagojenim izvajanjem in $z$ dodatno strokovno pomočjo $v$ izobraževalni program devetletne osnovne šole s prilagojenim izvajanjem in $z$ dodatno strokovno pomočjo smo začeli eno šolsko leto pred samim prehodom. $\mathrm{Za}$ začetek smo skupaj z vrtcem in s strokovnimi delavci Centra IRIS pripravili celostno oceno otrokovega funkcioniranja, s poudarkom na oceni funkcionalnosti vida, ki je služila tudi kot poročilo vrtca o otroku za postopek usmerjanja, ki so ga starši sprožili na območni enoti Zavoda Republike Slovenije za šolstvo. Po izpeljavi celostne ocene in pripravi tranzicijske mape najpomembnejših dokumentov smo ponovno navezali stik s starši in jih prosili za soglasje za posredovanje ključnih podatkov o otroku bodoči šoli. Po prejetem soglasju je sledil razgovor $z$ otrokom, $s$ katerim smo želeli izvedeti njegove želje in strahove pri prehodu. Učenec je med pogovorom izrazil željo po

Preglednica 1 Koraki prehoda

1 Sodelovanje s starši in vrtcem

2 Celostna ocena

3 Priprava tranzicijske mape

4 Uvodni sestanek in izobraževanje za učiteljski zbor

5 Obisk na šoli

6 Razgovor z otrokom

7 Prilagajanje šolskega okolja

8 Izposoja pripomočkov

9 Izdelava individualiziranega programa dela 
Preglednica 2 Zbirnik osnovnih informacij o otroku in priporočenih prilagoditev, ki smo ga predali učiteljem

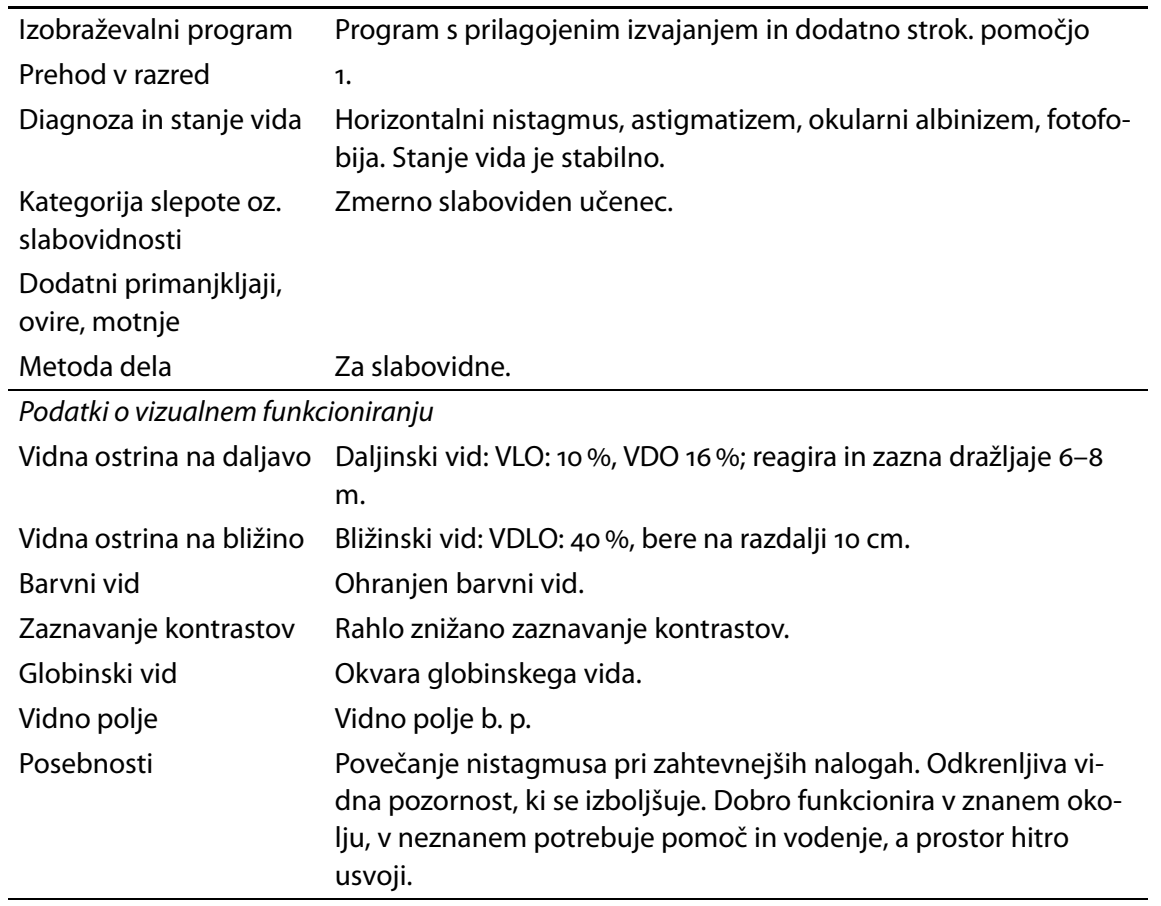

Nadaljevanje na naslednji strani

predhodnem obisku bodoče šole, kar smo tudi realizirali v sklopu ur dodatne strokovne pomoči, natančneje v sklopu treninga orientacije in mobilnosti.

Naslednji korak je obsegal delo s šolo na več ravneh: od uvodnega sestanka do dogovora z vodstvom šole glede izobraževanja za učiteljski zbor in predstavitve posebnih potreb bodočega prvošolca. Ker deček živi v ruralnem okolju in zaradi bližine vrtca, ki ga je obiskoval, se je večina zaposlenih na šoli že srečala z njim in so imeli na izobraževanju pripravljena konkretna vprašanja o njegovem funkcioniranju pri šolskem delu in v življenju nasploh. Skupaj smo se dogovorili tudi za pregled in prilagajanje šolskega okolja z namenom izboljšanja varnosti pri samostojnem gibanju in z vidika prilagajanja kontrastnosti (oz. izboljšanja vidnosti) prostorov, po katerih se bo gibal. Šola je pred začetkom novega šolskega leta oddala tudi vlogo za izposojo specialnih pripomočkov (npr. bralna mizica, elektronska lupa) na Center IRIS in s tem optimalno pripravila inkluzivno okolje.

$\mathrm{Na}$ koncu je sledila še izdelava individualiziranega programa dela, ki ga je novoimenovana strokovna skupina predstavila staršem. Pred vključitvijo $\checkmark$ prvi razred nismo izpeljali predstavitve otrokovih posebnih potreb za vr- 
Preglednica 2 Nadaljevanjes prejšnje strani

\begin{tabular}{|c|c|}
\hline $\begin{array}{l}\text { Časovne } \\
\text { prilagoditve }\end{array}$ & $\begin{array}{l}\text { Potrebuje: več časa za opazovanje in za seznanjanje z novimi predmeti, vse- } \\
\text { binami, materiali, več časa pri športnih aktivnostih, več časa pri vključeva- } \\
\text { nju v igro in druge dejavnosti ter seznanjanju z njimi, do } 50 \% \text { več časa pri } \\
\text { preverjanju in ocenjevanju znanja. }\end{array}$ \\
\hline $\begin{array}{l}\text { Prostorske } \\
\text { prilagoditve }\end{array}$ & $\begin{array}{l}\text { Stalni prostor v garderobi in pri obrokih, zagotovitev ustreznega mesta pri } \\
\text { pouku (z upoštevanjem možnosti boljše osredotočenosti na šolsko delo - } \\
\text { v bližini strokovne delavke in bliže tabli, sedi tako, da na dogajanje gleda z } \\
\text { boljšim očesom), primerna osvetlitev oz. zatemnitev prostora - možnost re- } \\
\text { guliranja naravne svetlobe z žaluzijami, preprečitev bleščanja, markantne } \\
\text { oznake učilnice, telovadnice in telovadnega orodja, markantna oznaka gar- } \\
\text { derobnega prostora, označeni nivojski prehodi (npr. stopnice), dodatna od- } \\
\text { lagalna miza pri pouku. }\end{array}$ \\
\hline $\begin{array}{l}\text { Didaktično- } \\
\text { metodične } \\
\text { prilagoditve }\end{array}$ & $\begin{array}{l}\text { Uporaba prilagojenih učbenikov za slabovidne, uporaba prilagojenih ze- } \\
\text { mljevidov, poenostavljeno slikovno gradivo, prilagoditev tabelskih slik, } \\
\text { uporaba flomastrov, markerjev ali bralnih ravnilc, možnost uporabe ustre- } \\
\text { znih informacijsko-komunikacijskih pripomočkov (računalnik) in gradiv v } \\
\text { elektronski obliki, barvne fotokopije, format listov A4, pisava ARIAL 18, prila- } \\
\text { gojeno izvajanje in ocenjevanje pri športu in drugje, kadar se zahteva upo- } \\
\text { rabo globinskega vida, možnost delnega poslušanja zvočnih knjig za do- } \\
\text { mače branje, toleranca natančnosti } 5 \text { stopinj in } 5 \text { mm pri geometriji, začasni } \\
\text { spremljevalec (za aktivnosti, ki potekajo izven šole, npr. kulturni dan, špor- } \\
\text { tni dan ...), poudarek na izkustvenem učenju - več terenskega dela, ekskur- } \\
\text { zij, možnost razbremenitve oči z vajami za sproščanje. }\end{array}$ \\
\hline Pripor & $\begin{array}{l}\text { Pisala z močno sledjo, prilagojeni učbeniki za slabovidne, računalnik s pro- } \\
\text { gramsko opremo za slabovidne, bralna mizica ali miza z dvižno ploskvijo, } \\
\text { zvezki s poudarjenim črtovjem, korekcijska in sončna očala, kapa s šiltom } \\
\text { pri gibanju na prostem, UV zaščitna krema pri gibanju na prostem, lupa 4D, } \\
\text { mat papir in mat folije za plastificiranje, geometrijski pribor za slabovidne. }\end{array}$ \\
\hline
\end{tabular}

stnike, saj je celotna skupina, v katero je bil deček vključen v vrtcu, prešla tudi v prvi razred in potrebe po tem ni bilo.

Konec avgusta, tik pred začetkom novega šolskega leta, se je pojavila ideja o tem, da za strokovne delavce, ki vstopajo v stik z učencem, strnemo najpomembnejše informacije o učencu na enem mestu, ki jim bo vedno na voljo. Tako smo oblikovali zbirnik osnovnih informacij o otroku in priporočenih prilagoditev ter ga vstavili $v$ dnevnik oddelka (preglednica 2). Na tak način so informacije ves čas dostopne trenutnemu učitelju v oddelku, kar se je pokazalo kot dobra praksa tudi pri ostalih učencih s slepoto in slabovidnostjo.

\section{Sklepne ugotovitve}

Izhajajoč iz raziskave, izkušenj in primerov dobrih praks lahko sklenemo, da za uspešen prehod oseb s posebnimi potrebami med različnimi ravnmi ali programi izobraževanja lahko izpostavimo tri bistvene sklope dejavnikov: (1) 
značilnosti otrokovih posebnih potreb in osebnostnih lastnosti, (2) značilnosti posameznikovega ožjega in širšega socialnega okolja ter (3) predhodna priprava vzgojno-izobraževalne institucije, v katero se posameznik vključuje.

Ugotavljamo, da je v proces prehoda med različnimi ravnmi in programi izobraževanja osebe s posebnimi potrebami vključeno veliko število udeležencev - tako posameznik in njegova družina kot večje število strokovnih delavcev. Nadalje ugotavljamo, da imajo strokovni centri, npr. centri za zgodnjo obravnavo in strokovni centri za različne vrste posebnih potreb ( $v$ našem primeru Center IRIS), ključno vlogo pri procesu tranzicije, saj med seboj povezujejo deležnike in koordinirajo postopek tranzicije. Najpogosteje se v vlogi ključnega izvajalca oz. koordinatorja pojavi izvajalec dodatne strokovne pomoči, še posebej ko govorimo o zelo specifičnih vrstah posebnih potreb, kot so npr. slepota in slabovidnost ali gluhoslepota, pri katerih svetovalni delavci nimajo ustreznih znanj in veščin, da bi v celoti vodili postopke tranzicije.

S študijo primera smo potrdili, da je najprimernejši način podajanja informacij kombinirani način ustnega in pisnega informiranja vseh udeležencev. Pri stiku z udeleženci v živo smo predstavili celostno funkcioniranje otroka, razrešili marsikatero dilemo in odgovorili na vprašanja, ki so se porajala udeležencem izobraževanja. Z zbirnikom pisnih informacij pa smo omogočili dostop do ključnih podatkov vsem strokovnim delavcem $v$ vsakem trenutku dela $v$ oddelku, $v$ katerega je učenec vključen. Glede na omejitve varovanja osebnih podatkov predlagamo, da se ključne informacije strne $v$ obliki tranzitne mape učenca. Predlagamo, da tranzitna mapa posameznika vsebuje informacije o zdravstvenih posebnostih in celostno oceno funkcioniranja.

Nakazati želimo tudi na omejitve in pomanjkljivosti naše raziskave. Ugotovili smo, da bi učenca lahko postavili v aktivnejšo vlogo pri samem načrtovanju prehoda, v smislu večjega upoštevanja njegovih osebnih potreb in načrtovanja posameznih korakov (predvsem časovnega obiska na šoli). Veščine aktivnega sodelovanja pri upravljanju lastnega življenja, ki jih otrok pridobi tekom šolanja, pogosteje uporabi v odraslosti, npr. v času zaposlovanja in prehoda na trg dela, kar zagotovo pozitivno vpliva tudi na splošen dvig kakovosti življenja ne le osebe s slepoto, slabovidnostjo ali okvaro vidne funkcije, pač pa tudi vseh drugih skupin oseb s posebnimi potrebami.

\section{Literatura}

»Abinizem.« B. I. V Slovenski medicinski slovar. Univerza v Ljubljani, Medicinska fakulteta. https://www.termania.net/iskanje?query=albinizem\&Searchln $=$ All.

Anderson, S., S. Boigon, K. Davis in C. deWaard. 2007. The Oregon Project for 
Preschool Children Who Are Blind or Visually Impaired. 6. izd. Medford, OR: Southern Oregon Education Service District.

»Astigmatizem.« B. I. V Slovenski medicinski slovar. Univerza v Ljubljani, Medicinska fakulteta. https://www.termania.net/iskanje?query=astigmatizem \&Searchln=All.

Belote, M. 2004. "Successful transitions Between Programs." California DeafBlind Services: Fact Sheet. http://files.cadbs.org/200000124-b4071b5009/ 36TransitionsPrograms.pdf.

But, B., ur. 2005. Vodnik po pravicah slepih in slabovidnih, ki izhajajo iz slovenske zakonodaje. Ljubljana: Zveza društev slepih in slabovidnih Slovenije.

Cavenaugh, B., in J. M. Giesen. 2012. »A Systematic Review of Transition Interventions Affecting the Employability of Youths with Visual Impairments." Journal of Visual Impairment and Blindness 106 (7): 400-413.

Center IRIS. 2020. "Strokovni center za celostno podporo otrokom in mladostnikom z okvaro vida ter otrokom in mladostnikom s primanjkljaji na posameznih področjih učenja.« http://strokovnicenter.splet.arnes.si/files/ 2017/10/Bro\%C5\%A1ura-Strokovni-center_2020.pdf.

Čelešnik Kozamernik, N., in S. Češarek. 2020. Smernice pri prehodih. Ljubljana: Center IRIS.

»Fotofobija.« B. I. V Slovenski medicinski slovar. Univerza v Ljubljani, Medicinska fakulteta. https://www.termania.net/iskanje?query=fotofobija\&Searchln =All.

Maljevac, M. 2018. »Značilnosti in dejavniki socialnega prilagajanja slepih in slabovidnih otrok.« Doktorska disertacija, Univerza na Primorskem.

Maljevac, M., in D. Žunič. 2017. „Sensitization of the Social Environment in Kindergartens as One of the Fundamental Principles of Work in Early Intervention in Children with Visual Impairments.« Prispevek predstavljen na Eurlyaid Conference 2017 - Early Childhood Intervention for Meeting Sustainable Development Goals of the New Millennium. Beograd, Srbija, 6.8. oktober.

Mohorko, A. (2016). »Vloga tiflopedagoga pri prehodu učenca s slabovidnostjo iz vrtca v osnovno šolo.« Magistrsko delo, Univerza v Ljubljani.

»Nistagmus.« B. I. V Slovenski medicinski slovar. Univerza v Ljubljani, Medicinska fakulteta. https://www.termania.net/iskanje?query=nistagmus\&Searchln =All.

Stirn Kranjc, B., V. Raič, U. Lah, T. Murn, D. Žunič in A. Pinterič. 2015. »Slepi in slabovidni otroci oz. otroci z okvaro vidne funkcije. «V Kriteriji za opredelitev vrste in stopnje primanjkljajev, ovir oz. motenj otrok s posebnimi potrebami, ur. N. Vovk-Ornik, 8-10. Ljubljana: Zavod Republike Slovenije za šolstvo.

Texas School for the Blind and Visually Impaired. B. I. https://www.tsbvi.edu/ career-education-items/3269-how-can-i-participate-in-transition-planning.

Zakon o usmerjanju otrok s posebnimi potrebami (ZUOPP-1). 2011. Uradni list 
Republike Slovenije, št. 58. https://www.uradni-list.si/1/objava.jsp?sop=2011 -01-2714.

Zakon o varstvu osebnih podatkov (ZVOP-1-UPB1). 2007. Uradni list Republike Slovenije, št. 94. https://www.uradni-list.si/1/objava.jsp?sop=2007-01 $-4690$.

Zupančič, M., in Kavčič, T. 2007. Otroci od vrtca do šole: razvoj osebnosti in socialnega vedenja ter učna uspešnost prvošolcev. Ljubljana: Znanstvenoraziskovalni inštitut Filozofske fakultete.

Zupančič, M., A. Podlesek in T. Kavčič. 2018. „Child Personality - Adjustment Associations at the Transition from Kindergarten to School: Evaluating the Vulnerability and the Scar Model.« Child Indicators Research 11 (1): 97-116.

\section{Planning and Structuring of Transitions between Different Levels of Education for Persons with Special Needs}

Inclusion of persons with special needs into the education system is a great challenge both to them, their family members, educators and everyone who will work with them in any way during their education process. Careful planning and good structuring of the transitions between different levels or programs of education can alleviate the distress and troubles of everyone involved. This article presents some recommendations for the planning and structuring of the transitions, focusing on the user's needs. It also highlights the tasks and roles of individual educators, as well as provides a case study of a good practice example to support the guidelines. The good practice example covers the whole presentation of the planning and structuring of the transition of a partially sighted child from the preschool program with an adjusted implementation and additional professional assistance into a nine-year primary school education program with an adjusted implementation and additional professional assistance.

Keywords: persons with special needs, transitions, planning and structuring, good practice example 